\title{
Correction
}

\section{Correction to: A hybrid approach to identifying and assessing interactions between climate action (SDG13) policies and a range of SDGs in a UK context}

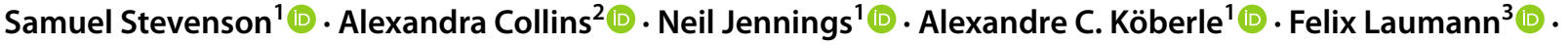 \\ Anthony A. Laverty ${ }^{4}(\mathbb{C})$ Paolo Vineis ${ }^{5}$. Jeremy Woods ${ }^{2}$ (I) . Ajay Gambhir ${ }^{1}(\mathbb{C}$
}

Published online: 29 November 2021

(c) The Author(s) 2021 OPEN

\section{Correction to: Discover Sustainability (2021) 2:43 \\ https://doi.org/10.1007/s43621-021-00051-w}

Following the delivery of the original article [1] for publication, we were informed that the following changes were still needed to it:

1. Author Alexandre Koberle's name should be corrected to "Alexandre C. Köberle", as shown in the author list of this "Correction".

2. Affiliation 6 should be deleted, since this was a duplicate of affiliation 2 "Centre for Environmental Policy, Imperial College London, Weeks Building, 16 - 18 Prince's Gardens, London SW7 1NE, UK". The superscripted "6" next to author Jeremy Woods's name should therefore be changed to "2", as shown in the author list of this "Correction".

3. The "Authors' contributions" section should read: "SS and AG designed the study. SS led the research and manuscript writing, including preparing text, figures, tables and supplementary material, with support from AG. All authors advised on the study design and provided feedback and advice throughout the study and writing of the manuscript. All authors read and approved the final manuscript".

4. The "Accessed" date for references 11, 15, 19, 22 and 23 should be corrected to "October 2020".

The original article has now been updated as above.

Open Access This article is licensed under a Creative Commons Attribution 4.0 International License, which permits use, sharing, adaptation, distribution and reproduction in any medium or format, as long as you give appropriate credit to the original author(s) and the source,

The original article can be found online at https://doi.org/10.1007/s43621-021-00051-w.

$\triangle$ Samuel Stevenson, s.stevenson@imperial.ac.uk; Alexandra Collins, alexandra.collins@imperial.ac.uk; Neil Jennings, neil.jennings@ imperial.ac.uk; Alexandre C. Köberle, a.koberle@imperial.ac.uk; Felix Laumann, f.laumann18@imperial.ac.uk; Anthony A. Laverty, a.laverty@imperial.ac.uk; Paolo Vineis, p.vineis@imperial.ac.uk; Jeremy Woods, jeremy.woods@imperial.ac.uk; Ajay Gambhir, a.gambhir@ imperial.ac.uk | ${ }^{1}$ Grantham Institute - Climate Change and the Environment, Imperial College London, Exhibition Road, London SW7 2AZ, UK. ${ }^{2}$ Centre for Environmental Policy, Imperial College London, Weeks Building, 16 - 18 Prince's Gardens, London SW7 1NE,

UK. ${ }^{3}$ Department of Mathematics, Imperial College London, Weeks Building, 16 - 18 Prince's Gardens, London SW71NE, UK. ${ }^{4}$ School of Public Health, Imperial College London, Reynolds Building, St Dunstan's Road, London W6 8RP, UK. ${ }^{5}$ School of Public Health, Imperial College London, St Mary's Hospital, Praed Street, London W2 1NY, UK. 
provide a link to the Creative Commons licence, and indicate if changes were made. The images or other third party material in this article are included in the article's Creative Commons licence, unless indicated otherwise in a credit line to the material. If material is not included in the article's Creative Commons licence and your intended use is not permitted by statutory regulation or exceeds the permitted use, you will need to obtain permission directly from the copyright holder. To view a copy of this licence, visit http://creativecommons.org/licenses/by/4.0/.

\section{Reference}

1. Stevenson S, Collins A, Jennings N, Köberle AC, Laumann F, Laverty AA, Vineis P, Woods J, Gambhir A. A hybrid approach to identifying and assessing interactions between climate action (SDG13) policies and a range of SDGs in a UK context. Discover Sustainability. $2021 ; 2: 43$. https://doi.org/10.1007/s43621-021-00051-w.

Publisher's Note Springer Nature remains neutral with regard to jurisdictional claims in published maps and institutional affiliations. 